\title{
Florid Suprascapular Neuropathy after Primary Rotator Cuff Repair Attributed to Suprascapular Notch Constriction in the Setting of Double Crush Syndrome
}

\author{
John G. Skedros ${ }^{1,2}$ Casey J. Kiser ${ }^{1} \quad$ Bryce B. Hill ${ }^{1}$ \\ ${ }^{1}$ Intermountain Medical Center, Salt Lake City, Utah, United States \\ 2 University of Utah Department of Orthopaedics, Salt Lake City, Utah, \\ United States \\ Address for correspondence John G. Skedros, MD, Utah Orthopaedic \\ Specialists, 5323 South Woodrow Street, Suite 200, Salt Lake City, UT \\ 84107, United States (e-mail: jskedrosmd@uosmd.com).
}

J Brachial Plex Peripher Nerve Inj 2015;10:e66-e73.

\begin{abstract}
This report describes a patient who had an open repair of a small supraspinatus tendon tear performed 6 months after an arthroscopic acromioplasty with debridement had failed to provide pain relief. Three months prior to the tendon repair, he had a two-level cervical spine discectomy and fusion ( $\mathrm{C} 4-5, \mathrm{C} 5-6)$ that improved his neck pain. Florid suprascapular neuropathy was detected 10 weeks after the open rotator cuff repair. Evidence of some nerve recovery resulted in a long period of observation. But unsatisfactory improvement warranted decompression of the suprascapular notch, which was found to be very stenotic. At surgery, there was no evidence of neuroma,

Keywords

- suprascapular neuropathy

- rotator cuff tear

- shoulder pain

- suprascapular nerve

- supraspinatus

- double hit phenomenon

- double crush syndrome cyst, or other compressing lesion or tissue. Therefore, it was ultimately hypothesized that there was an exacerbation of a preexisting, but clinically unrecognized, entrapment of the suprascapular nerve in the suprascapular notch in the setting of cervical radiculopathy (primarily $\mathrm{C5}$ ). Retrospectively it was also concluded that had this compressive etiology been recognized, it would have favored prompt decompression rather than the long observation period. Three years was required to achieve a good result following suprascapular notch decompression. The underlying C 5 radiculopathy may have created a "double crush syndrome" that contributed to the propensity for injury and the prolonged recovery. There should be heightened awareness of this problem in patients who do not have satisfactory improvement in shoulder pain from previous shoulder and neck surgery.
\end{abstract}

\section{Background}

Several studies have shown that suprascapular neuropathy can occur in a significant percentage of patients with largeto-massive rotator cuff tears, ${ }^{1-5}$ but is a rare complication following primary rotator cuff repairs even when tears are massive ${ }^{6,7}$ In a study of 26 patients with massive cuff tears who were evaluated with preoperative electrodiagnostic studies, 7 (38\%) had isolated suprascapular injury. ${ }^{3}$ In six of

received

June 20, 2014 accepted after revision

September 21, 2015

published online

November 6, 2015
$10.1055 / \mathrm{s}-0035-1567807$ ISSN $1749-7221$. these patients, the neuropathy improved after repair (the seventh was irreparable). Costouros et $\mathrm{al}^{3}$ speculated that improvement occurred because the repair untethered the suprascapular nerve (SSN) from being compressed at the base of the scapular spine (-Fig. 1). When improvement does not occur, or when postoperative neuropathy occurs but is not detected preoperatively (as in this report), the differential diagnosis is broadened to include (1) direct

Copyright $\odot 2015$ Georg Thieme Verlag KG Stuttgart · New York
License terms

(@) (1) $\circledast$ 


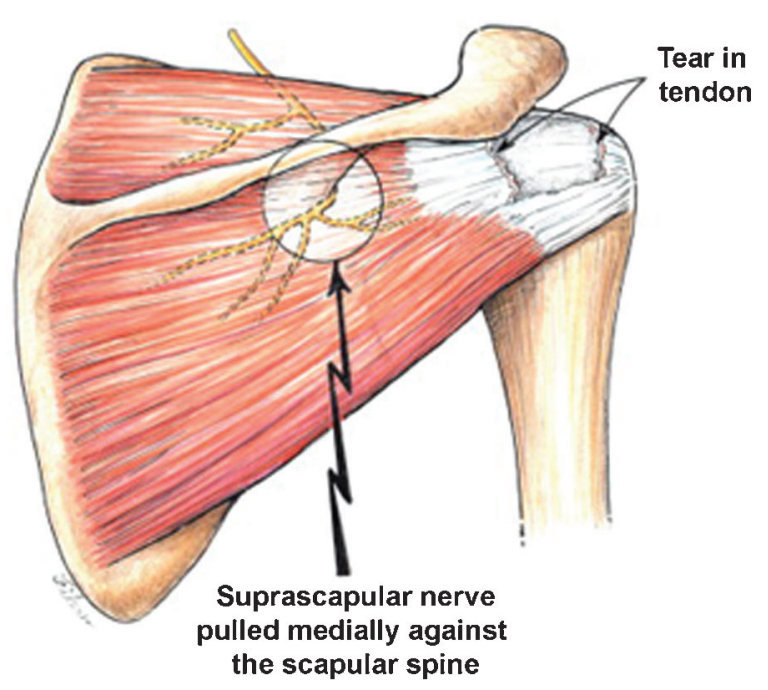

Fig. 1 Medial retraction of the suprascapular nerve (SSN) caused by a large-to-massive rotator cuff tear. Illustration of how the SSN can experience traction by being pulled medially at the base of the scapular spine following medial and inferior retraction of a large-to-massive tear. In some cases, repairing these tears can un-tether the nerve by mobilizing it laterally. Not only has this explanation been contested, ${ }^{8}$ but it is also not applicable in our patient because his cuff tear was small and significant suprascapular neuropathy occurred after the cuff repair. Reproduced from Costouros et $\mathrm{al}^{3}$ with permission of Elsevier Limited.

iatrogenic injury, (2) cervical radiculopathy, (3) brachial plexitis, (4) compression by an extrinsic mass such as a hematoma or ganglion cyst not detected preoperatively, and (5) indirect iatrogenic injury secondary to cuff-repairrelated traction of the SSN that was constricted in the suprascapular notch. ${ }^{9}$ This latter possibility appears to have been an important factor in our unusual case, where repair of the rotator cuff exacerbated a preexisting, but preoperatively undetected, SSN dysfunction.

\section{Case Presentation}

A healthy 62-year-old (height: $1.83 \mathrm{~m}$; weight: $98.4 \mathrm{~kg}$; body mass index: $22 \mathrm{~kg} / \mathrm{m}^{2}$ ) right-hand-dominant man, who was an accountant and avid golfer, was referred to our clinic with a chief complaint of left shoulder pain. There was no history of shoulder or neck trauma. Thirteen years ago, an arthroscopic acromioplasty was performed on his left shoulder, and 6 months prior to this first clinic visit a revision arthroscopic acromioplasty with cuff tendon debridement was performed for recurrent pain, but did not help. His diagnosis had been stage-two subacromial impingement syndrome. ${ }^{10}$ The pain was achy and occasionally sharp and was distributed over the anterior and superiorposterior aspects of the shoulder. There was a mildly positive left-side Spurling sign, but there was no winging of the scapula, and liftoff and glenohumeral instability tests were negative. Active range of motion was 150-degree flexion and 135-degree abduction, and manual muscle tests showed normal strength. Pain was moderate with impingement (Neer) and impingement reinforcement (Hawkins-Kennedy) maneuvers. His initial American Society of Shoulder and Elbow Surgeons (ASES) score was 64 (best $=100$ ) and other measures of general health and shoulder function are listed in - Table 1. ${ }^{11-16}$

Images from a magnetic resonance (MR) scan obtained 7 months prior are shown in - Fig. 2A, B. An MR scan performed 6 weeks prior to his first visit showed a small tear of the supraspinatus tendon with mild muscle atrophy ( - Fig. 2C-E). Both scans showed mild fatty degeneration of the infraspinatus (- Fig. 2B, C). A subsequent neck MR scan showed disk bulges/ herniations at $\mathrm{C} 2-3, \mathrm{C} 3-4, \mathrm{C} 4-5$, and $\mathrm{C} 5-6$. A neurosurgeon then performed two-level disk fusions (C4-6), which relieved the neck pain but only mildly reduced the shoulder pain. Three months later (December 2006), the senior author (J. G. S.) performed arthroscopic debridement of anterior labral fraying and open repair of a small supraspinatus tear. The tear was retracted $15 \mathrm{~mm}$ and was easily mobilized without requiring tissue release beyond the glenoid labrum. Two suture anchors were used to affect a quasi-double-row repair. ${ }^{19}$ Active motion was not allowed for 8 weeks.

At 10 weeks postsurgery, there was substantial left shoulder weakness with attempts at active motion. Although the deltoid contracted well, there was (1) atrophy in the infraspinatus muscle, and strength of 3/5 in external rotation and $3-/ 5$ in elevation in the plane of the scapula, as well as (2) mildly positive left-side Spurling sign. The differential diagnosis included iatrogenic injury, extrinsic compression (e.g., hematoma, cyst, etc.), brachial plexopathy, and/or concomitant cervical nerve-root compression. ${ }^{20,21}$ A nerve conduction study and electromyography (NCS/EMG) showed findings consistent with SSN injury at the level of the suprascapular notch with absence of evidence of re-innervation. MR scans obtained of the left brachial plexus and shoulder showed humeral head elevation suggesting weakness of the superior rotator cuff ( - Fig. 3 ) but no evidence of (1) a spaceoccupying lesion along the SSN, (2) injury of the brachial plexus and its nerve branches, ${ }^{22-24}$ or (3) unusual morphology of the suprascapular notch or transverse scapular ligament (retrospective examination showed that these scans were not sufficient to detect an anomaly of the notch).

At 105 days after shoulder surgery, the patient saw his neurosurgeon for a 7-month follow-up and the cervical fusion had healed. At 138 days after shoulder surgery, there was increased burning and aching that radiated across the posterior and lateral aspects of the shoulder and upper arm. Voluntary infraspinatus contractions were now more obvious. Active shoulder flexion and abduction were $<80$ degrees each. The changing pain intensity and characteristics were presumed to reflect SSN recovery for which Lyrica (pregabalin) $75 \mathrm{mg}$ twice/ day was prescribed. At 162 days after surgery, the neuropathic pain was significantly decreased and usually did not require medication; however, there was no improvement in strength in flexion or external rotation.

At 213 days after cuff repair, results of another NCS/EMG revealed findings that could not be explained by an isolated suprascapular neuropathy: (1) denervation potentials in deltoid, rhomboids, and C5 cervical paraspinal muscles, as well as in the supraspinatus, suggesting C5 radiculopathy; (2) small amplitude fibrillation potentials in the abnormal 


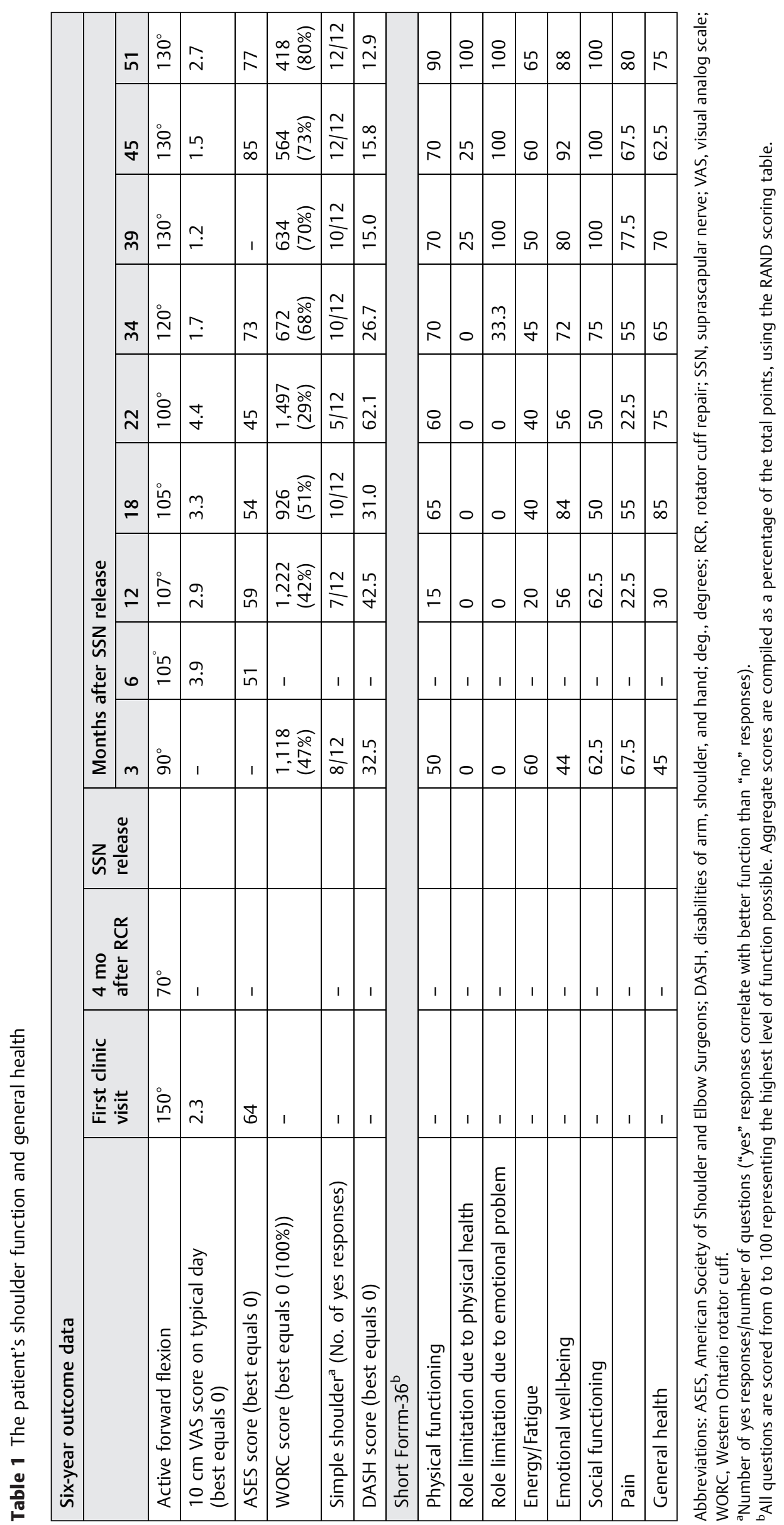



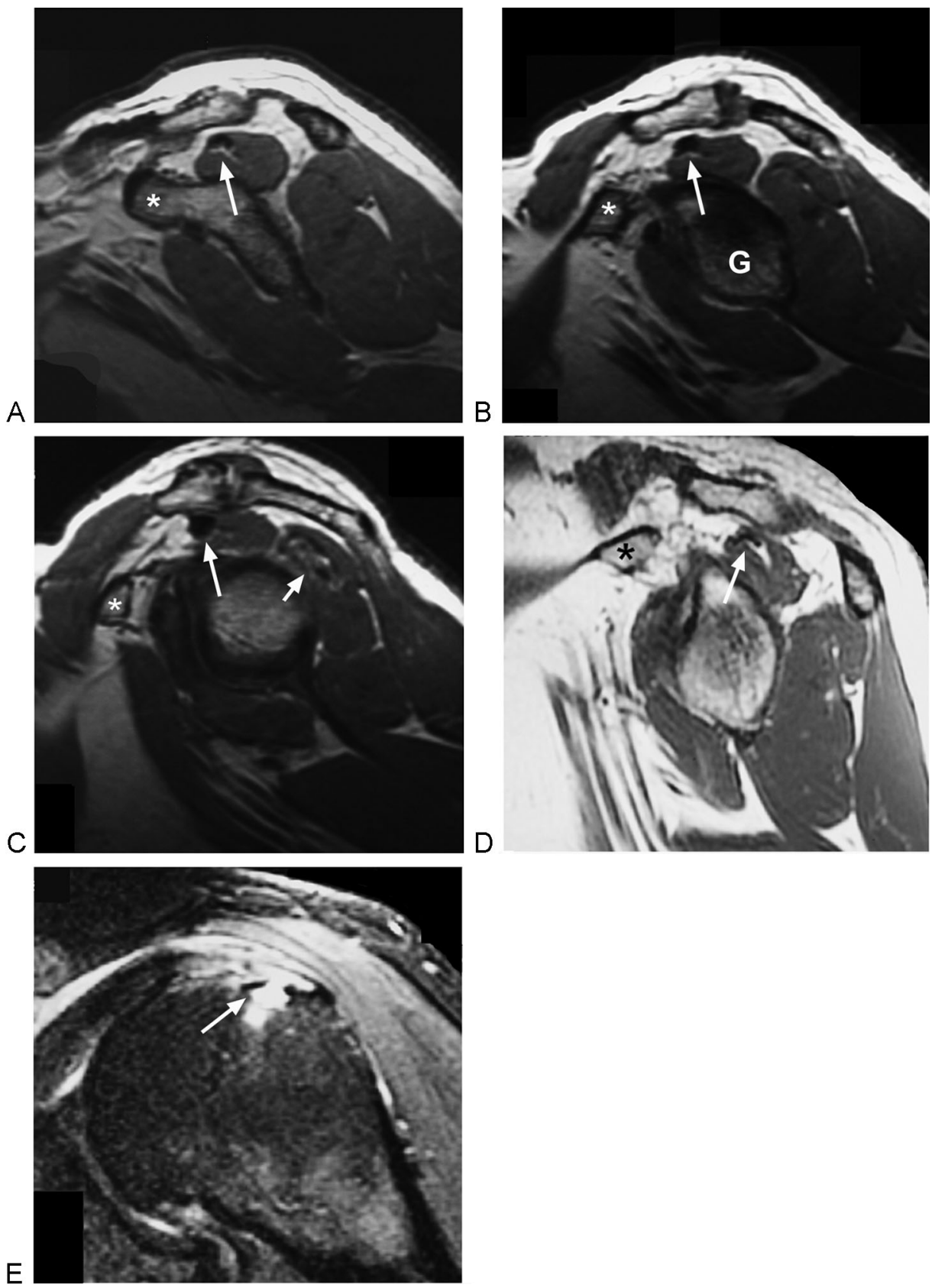

Fig. 2 MR images prior to rotator cuff repair. MR images $16(A-C)$ and 10 (D, E) months prior to cuff repair; asterisk indicates the coracoid. (A, B) Evidence of scarring in the supraspinatus (white arrows) 16 months preoperation. ( $\mathrm{G}=$ glenoid). (C) Mild fatty degeneration (short arrow) 17,18 of the infraspinatus. Scarring in the supraspinatus (longer arrow). (D) Scar tissue is seen in (A) and (B) (arrow), and mild fatty degeneration ${ }^{17,18}$ of the supraspinatus is seen 10 months preoperation. (E) Small supraspinatus tear (arrow).

muscles, and complex repetitive discharges in the deltoid indicating chronic neuropathy; and (3) evidence of re-innervation in the abnormal muscles. There was also no evidence of conduction block along the suprascapular and axillary nerves. A diagnostic/therapeutic suprascapular notch injection with local anesthetic and a corticosteroid was recommended. However, the patient's pain (but not strength) improved, causing him to cancel the injection. In view of evidence of early nerve recovery, and in the perspective that intraoperative trauma had somehow occurred to the SSN, a consulting surgeon specializing in peripheral neuropathies recommended to continue nonoperative management. This recommendation reflected the general conclusions of Antoniou et $\mathrm{al}^{25}$ who, in their analysis of the functional outcome of 23 patients, suggested that traumatic lesions of the SSN can have equivalent responses to operative and nonoperative treatment. (But, as discussed later, it was ultimately concluded that prompt scapular notch decompression would have been best for our patient.)

By 322 days after surgery, the pain recurred with greater intensity. A suprascapular notch injection with $0.25 \%$ bupivacaine was done using computed tomography (CT) guidance 

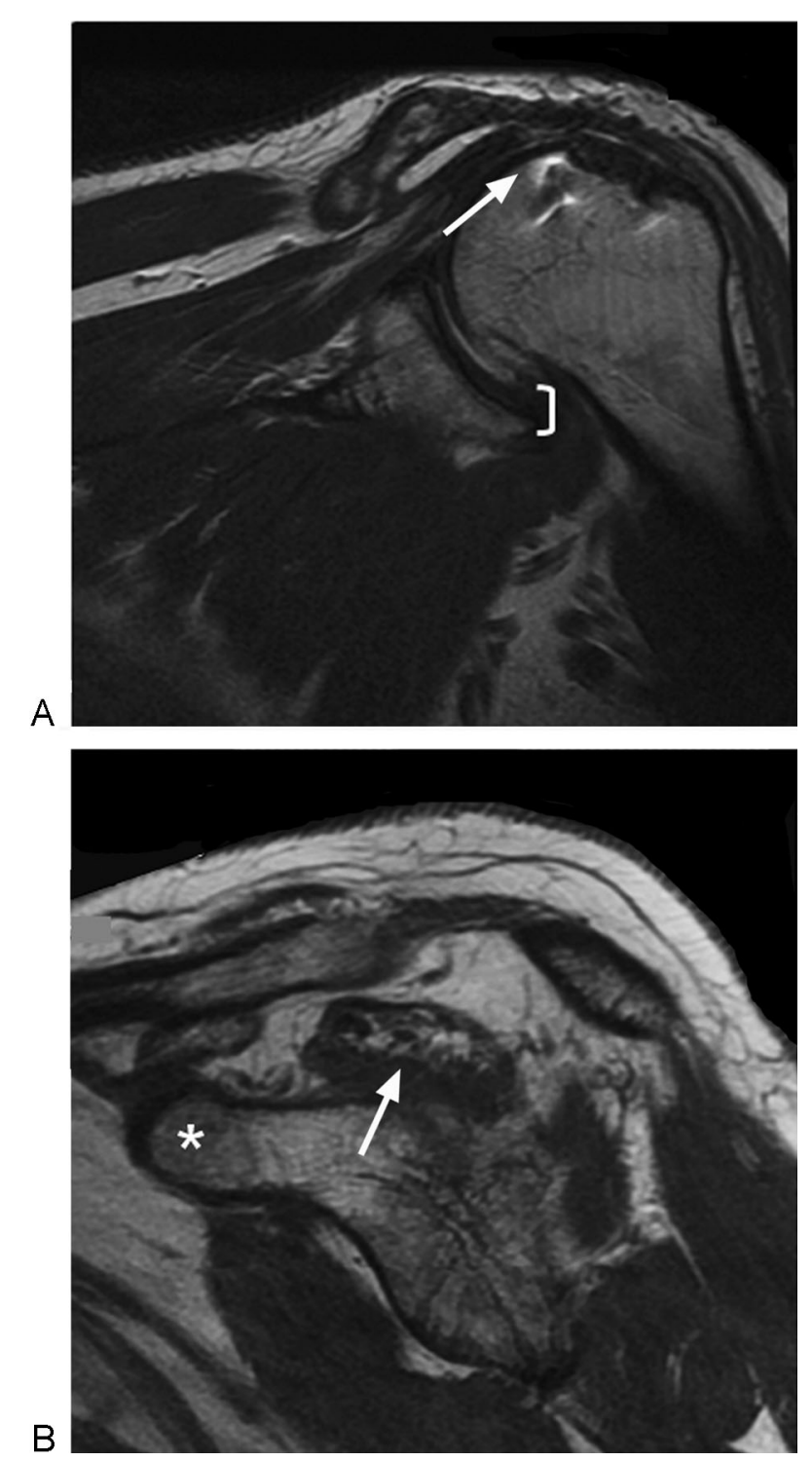

Fig. 3 MR images 4 months after rotator cuff repair. (A) Elevation of the humeral head (white bracket) and signal changes, and a possible defect in the supraspinatus insertion (arrow). (B) Moderate supraspinatus fatty degeneration (arrow). Asterisk indicates the coracoid.

and this yielded excellent, but temporary, improvement. An open surgical decompression of the suprascapular notch was performed (nearly 1 year after the cuff repair, - Table 1) by the same consulting surgeon. The nerve was grossly compressed beneath a hypertrophic ligament in a narrowed suprascapular notch ( - Fig. 4$)^{26}$ and it dramatically protruded upward after ligament transection. The first motor branch to the supraspinatus was distal to the notch ${ }^{28}$ and the supraspinatus motor branches were intact. There was no evidence of neuroma or other gross neural, perineural, or vascular pathology, variation, or anomaly, and no compression caused by the deep fascia proximal or distal to the suprascapular notch or by the tissues forming the spinoglenoid notch. ${ }^{26,29}$ Consequently, further surgical exploration ${ }^{26,30}$ was not necessary. The transverse scapular ligament was excised and the notch was enlarged. ${ }^{25,31}$ During the following
6 months, the burning pain improved significantly but the weakness persisted.

At 22 months after notch decompression, the pain and function had worsened. A second postoperative MR scan showed increased fatty degeneration of the supraspinatus and infraspinatus (-Fig. 5). By contrast, substantial overall improvement occurred at 27 months-the pain had almost completely subsided and strength significantly improved. In fact, he was able to remodel his home (manual labor for several months) without significant discomfort. Active forward flexion was 120 degrees, but early fatigue with overhead motion was reported. At final follow-up at 4.5 years after notch decompression, he had reached a plateau in motion and strength $(4+/ 5)$ and the pain was minimal/tolerable except when golfing. An axillary lateral radiograph showed evidence of glenohumeral arthritis, which likely contributed to this activity related pain.

\section{Conclusion}

Among the various potential factors contributing to our patient's shoulder dysfunction, what is clear is that the SSN was constricted in a narrowed suprascapular notch. Because there are no data suggesting that a narrowed notch and hypertrophic transverse scapular ligament result from indirect iatrogenic injury during routine open repair of a small cuff tear, ${ }^{32}$ we conclude that the SSN was compressed in the notch prior to the repair. What likely occurred was that first the preexisting narrowed notch and hypertrophied superior transverse ligament made the nerve prone to injury even after typically inconsequential minor perturbation (e.g., nerve and other tissue motion during the rotator cuff repair). ${ }^{28}$ Second, a vicious cycle ensued that produced focal swelling that interfered with axonal transport and caused vascular compromise, ultimately leading to more pronounced edema along the nerve with resulting distal muscle dysfunction. The anatomical bottleneck then became even more constrictive pronouncing the pathology, which in our patient's case resulted in a functionally (but not morphologically) complete lesion. While timely decompression of such a lesion can frequently produce good results, the delay in our patient's surgical decompression likely contributed to the prolonged delay in achieving a good result. ${ }^{25,33}$

A significant amount of our patient's preoperative pain (i.e., before the cuff repair) was likely sensory dysfunction ${ }^{34,35}$ from notch constriction-consistent with descriptions of "tunnel syndrome of the SSN" or "carpal tunnel syndrome of the shoulder." ${ }^{26,36}$ Suprascapular neuropathy has been postulated to occur from excess motion of the scapula because the nerve is tethered to at least two, and often three, anatomic locations: the suprascapular notch, the spinoglenoid notch, and Erb point in the neck. ${ }^{27,37,38}$ However, observations by Rengachary et $\mathrm{al}^{27,38}$ in fresh cadavers revealed no obvious movement of the SSN across the suprascapular notch with extreme shoulder motion, reflecting the fact that the neurovascular pedicle is fixed to the periosteum in the notch and to the supraspinous fossa. They speculated that SSN injury more likely results from kinking against the ligament (the "sling effect") because of its close apposition to 

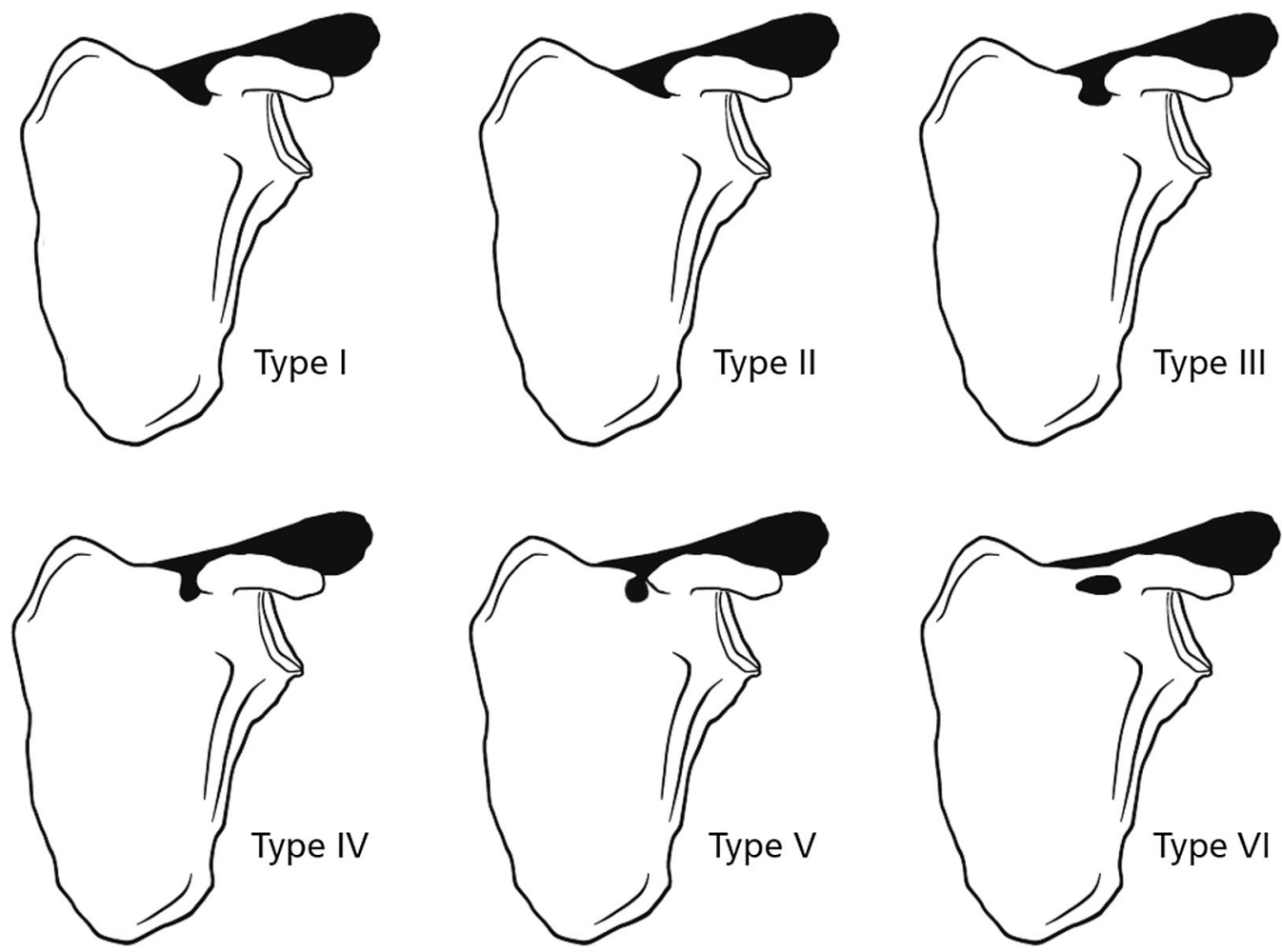

Fig. 4 Types of suprascapular notch morphologies. These original drawings are based on the photographs in Rengachary et al. ${ }^{27}$ Type $V(6 \%$ incidence) was found in our patient at the time of notch decompression.

its sharp inferior border with shoulder depression, retraction, and hyperabduction. This "sling effect" might become even more pronounced when the SSN is also constricted within a stenotic notch like that in our patient.

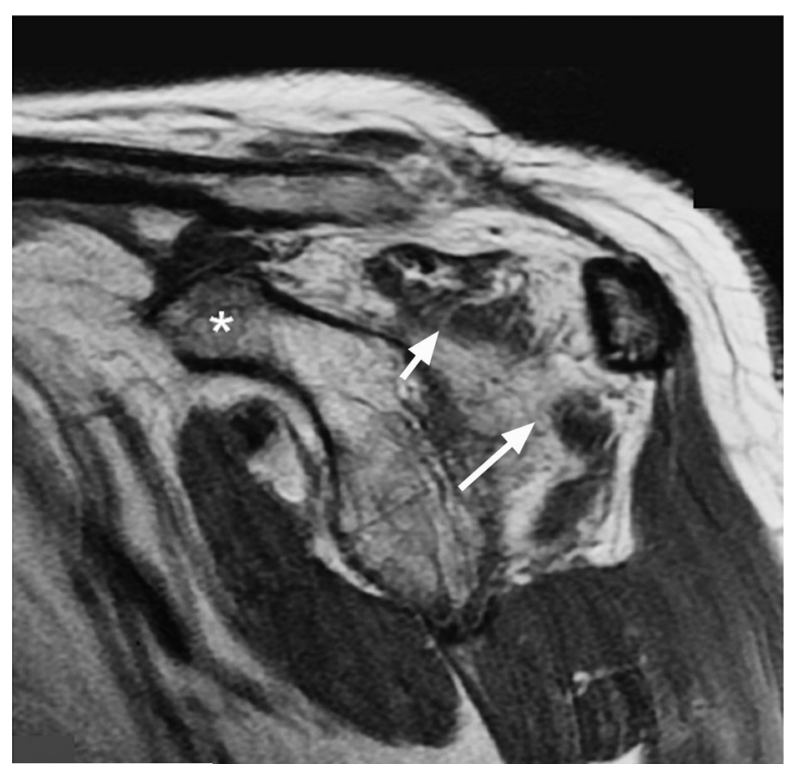

Fig. 5 MR image obtained 34 months after rotator cuff repair and 22 months after suprascapular notch decompression showed worsening of fatty degeneration of the supraspinatus (short arrow) and infraspinatus (long arrow). The coracoid is indicated with an asterisk.
Although a peripheral nerve can tolerate approximately $10 \%$ increase in its resting length before neurapraxia occurs, ${ }^{39}$ altered conduction can occur when a nerve is stretched beyond $6 \%$ of its resting length. ${ }^{40}$ Scarring of the neurovascular pedicle associated with some cuff tears can reduce the distance that the nerve can be stretched without injury. ${ }^{9}$ Support for the hypothesis that this is what happened in our patient includes: (1) his avid recreational activities (golf) causing repetitive trauma, potentially increasing constriction in his stenotic suprascapular notch, ${ }^{33,41,42}$ and (2) the scar-like tissue in the "intramuscular tendinous core" of the anterior supraspinatus ${ }^{43}$ (-Fig. 2) can reduce the ability to safely mobilize the tendon during repair. ${ }^{44-46}$ These factors may have contributed to SSN injury in our patient even though tendon mobilization was within the safe range in normal cases. ${ }^{28}$ The $\mathrm{C} 5$ axonal pathology is also potentially important because the SSN contains fibers primarily from C5 and C6. If the C5 radiculopathy caused impairment of SSN axonal transport, then it might have been more prone to neuropathy from peripheral constriction. This phenomenon is sometimes referred to as a "double crush syndrome" or the "double hit phenomenon." $4,47-49$

Because there were periods of improvement during his early postoperative course, a prolonged period of recovery was allowed. This opinion was based on the presumption that the SSN sustained intraoperative trauma and hence this opinion was consistent with the general conclusions of Antoniou et al. ${ }^{25}$ The SSN lesions in their 23 patients that were caused by trauma (including traction and direction closed injuries) showed no statistical difference in the response to operative $(n=12)$ and nonoperative $(n=11)$ treatment. But the $p$-value for this 
difference was not provided, leaving the reader with the impression that, based on the subsample means provided, the sample sizes were insufficient to discern clinically and statistically significant differences when all of these issues are considered: (1) trauma mechanism, (2) depth of nerve injury, (3) lesion level, (4) intraoperative electrophysiological evaluation result, and (5) microsurgical repair method chosen, which can have a significant effect on results obtainable (e.g., external neurolysis and/or nerve mobilization, vs. graft repair vs. end-to-end repair after neuroma excision). However, Antoniou et $\mathrm{al}^{25}$ did show that, in contrast to "traumatic lesions," "compressive lesions" attributable to suprascapular notch entrapment (which our patient had) had the best outcome with surgical decompression. Therefore, prompt scapular notch decompression would have been the best choice for our patient. This is supported by additional reports showing that when transverse scapular ligament release is done relatively soon after the diagnosis is made that milder muscle atrophy is more likely to subside along with shoulder pain. ${ }^{50}$ But when ligament release was delayed and there was advanced atrophy, the pain improved but not the atrophy.

Recent studies show that a large percentage of massive rotator cuff tears with significant muscle atrophy can have significant clinical improvement after surgical repair without SSN decompression. ${ }^{51}$ This is one reason why current guidelines for the preoperative workup of most rotator cuff tears do not include electrodiagnostic testing. ${ }^{4,5,8,9,32}$ But when functional deficits that do not resolve, and there are signs of a possible nerve lesion, easy and cost-effective electrodiagnostic studies as well as nerve imaging should be included early in the differential diagnostic workup. SSN impairment can be diagnosed quite well electrophysiologically by NCS/EMG, and well differentiated from C5 injury. In conjunction with MR imaging of supraspinatus/infraspinatus muscle wasting and high signal due to denervation edema, a concomitant nerve lesion can be readily diagnosed. If this is the case, then exploration and macro-/microsurgical decompression or nerve repair should follow promptly. In less clear cases, neuroimaging in the form of MR neurography of the notch area (thin slice, $1 \mathrm{~mm}$, in high resolution) or neurosonography, or both, can be used to enhance the ability to define the lesion. ${ }^{52,53}$ This includes the condition of the muscles (including wasting and fatty degeneration) and the nerve can be traced from its takeoff from the upper trunk to the notch area and beyond to reveal transection, neuroma, constriction, or edema.

In summary, our patient had an unusual postoperative course because of the exacerbation of preexisting entrapment of the SSN in the suprascapular notch. Three years was required to achieve a good result following suprascapular notch decompression, which was done nearly 1 year after the diagnosis was clearly established. There should be heightened awareness of this problem in patients who do not have satisfactory improvement in shoulder pain from previous shoulder and neck surgery, and this should prompt more immediate surgical decompression in some cases. The underlying C5 radiculopathy that our patient had may have created a "double crush syndrome" that contributed to the propensity for injury and prolonged recovery.

\section{Consent}

Written informed consent was obtained from the patient for written or electronic publication of this case report and any accompanying images. A copy of the written consent is available for review by the Editor-in-Chief of this journal.

\section{Competing Interests}

The authors declare that they have no competing interests.

\section{Authors' Contributions}

J. G. S.: Largely contributed to the literature review and writing of the case report as well as performed or directly participated in all aspects of the clinical management of the case.

C. J. K.: Contributed to the literature review and writing of the case report.

B. B. H.: Contributed to the literature review and writing of the case report.

\section{Acknowledgments}

We thank Dr. Stuart Willick and Dr. Kenneth Hunt for their criticisms of the manuscript.

\section{References}

1 Vad VB, Southern D, Warren RF, Altchek DW, Dines D. Prevalence of peripheral neurologic injuries in rotator cuff tears with atrophy. J Shoulder Elbow Surg 2003;12(4):333-336

2 Mallon WJ, Wilson RJ, Basamania CJ. The association of suprascapular neuropathy with massive rotator cuff tears: a preliminary report. J Shoulder Elbow Surg 2006;15(4):395-398

3 Costouros JG, Porramatikul M, Lie DT, Warner JJ. Reversal of suprascapular neuropathy following arthroscopic repair of massive supraspinatus and infraspinatus rotator cuff tears. Arthroscopy 2007;23(11):1152-1161

4 Boykin RE, Friedman DJ, Zimmer ZR, Oaklander AL, Higgins LD, Warner JJP. Suprascapular neuropathy in a shoulder referral practice. J Shoulder Elbow Surg 2011;20(6):983-988

5 Piasecki DP, Romeo AA, Bach BR Jr, Nicholson GP. Suprascapular neuropathy. J Am Acad Orthop Surg 2009;17(11):665-676

6 Cofield RH, Parvizi J, Hoffmeyer PJ, Lanzer WL, Ilstrup DM, Rowland CM. Surgical repair of chronic rotator cuff tears. A prospective long-term study. J Bone Joint Surg Am 2001;83$\mathrm{A}(1): 71-77$

7 Zanotti RM, Carpenter JE, Blasier RB, Greenfield ML, Adler RS, Bromberg MB. The low incidence of suprascapular nerve injury after primary repair of massive rotator cuff tears. J Shoulder Elbow Surg 1997;6(3):258-264

8 Collin P, Treseder T, Lädermann A, et al. Neuropathy of the suprascapular nerve and massive rotator cuff tears: a prospective electromyographic study. J Shoulder Elbow Surg 2014;23(1):28-34

9 Poberaj B, Kovacic L. The presence of suprascapular neuropathy in rotator cuff tears. International Journal of Shoulder Surgery 2007; $1: 58-63$

10 Neer CS II. Impingement lesions. Clin Orthop Relat Res 1983;(173): 70-77

11 Brazier JE, Harper R, Jones NM, et al. Validating the SF-36 health survey questionnaire: new outcome measure for primary care. BMJ 1992;305(6846):160-164

12 Kocher MS, Horan MP, Briggs KK, Richardson TR, O'Holleran J, Hawkins RJ. Reliability, validity, and responsiveness of the 
American Shoulder and Elbow Surgeons subjective shoulder scale in patients with shoulder instability, rotator cuff disease, and glenohumeral arthritis. J Bone Joint Surg Am 2005;87(9): 2006-2011

13 Kirkley A, Alvarez C, Griffin S. The development and evaluation of a disease-specific quality-of-life questionnaire for disorders of the rotator cuff: The Western Ontario Rotator Cuff Index. Clin J Sport Med 2003;13(2):84-92

14 Godfrey J, Hamman R, Lowenstein S, Briggs K, Kocher M. Reliability, validity, and responsiveness of the simple shoulder test: psychometric properties by age and injury type. J Shoulder Elbow Surg 2007;16(3):260-267

15 Hudak PL, Amadio PC, Bombardier C; The Upper Extremity Collaborative Group (UECG). Development of an upper extremity outcome measure: the DASH (disabilities of the arm, shoulder and hand) [corrected]. Am J Ind Med 1996;29(6):602-608

16 SooHoo NF, McDonald AP, Seiler JG III, McGillivary GR. Evaluation of the construct validity of the DASH questionnaire by correlation to the SF-36. J Hand Surg Am 2002;27(3):537-541

17 Gladstone JN, Bishop JY, Lo IK, Flatow EL. Fatty infiltration and atrophy of the rotator cuff do not improve after rotator cuff repair and correlate with poor functional outcome. Am J Sports Med 2007;35(5):719-728

18 Warner JJ, Higgins L, Parsons IM IV, Dowdy P. Diagnosis and treatment of anterosuperior rotator cuff tears. J Shoulder Elbow Surg 2001;10(1):37-46

19 Burkhead WZ Jr, Skedros JG, O'Rourke PJ, Pierce WA, Pitts TC. A novel double-row rotator cuff repair exceeds strengths of conventional repairs. Clin Orthop Relat Res 2007;461(461):106-113

20 Romeo AA, Rotenberg DD, Bach BR Jr. Suprascapular neuropathy. J Am Acad Orthop Surg 1999;7(6):358-367

21 Walsworth MK, Mills JT III, Michener LA. Diagnosing suprascapular neuropathy in patients with shoulder dysfunction: a report of 5 cases. Phys Ther 2004;84(4):359-372

22 Fritz RC, Helms CA, Steinbach LS, Genant HK. Suprascapular nerve entrapment: evaluation with MR imaging. Radiology 1992; 182(2):437-444

23 Zeiss J, Woldenberg LS, Saddemi SR, Ebraheim NA. MRI of suprascapular neuropathy in a weight lifter. J Comput Assist Tomogr 1993;17(2):303-308

24 Inokuchi W, Ogawa K, Horiuchi Y. Magnetic resonance imaging of suprascapular nerve palsy. J Shoulder Elbow Surg 1998;7(3): 223-227

25 Antoniou J, Tae S-K, Williams GR, Bird S, Ramsey ML, Iannotti JP. Suprascapular neuropathy. Variability in the diagnosis, treatment, and outcome. Clin Orthop Relat Res 2001;(386):131-138

26 Duparc F, Coquerel D, Ozeel J, Noyon M, Gerometta A, Michot C. Anatomical basis of the suprascapular nerve entrapment, and clinical relevance of the supraspinatus fascia. Surg Radiol Anat 2010;32(3):277-284

27 Rengachary SS, Burr D, Lucas S, Hassanein KM, Mohn MP, Matzke H. Suprascapular entrapment neuropathy: a clinical, anatomical, and comparative study. Part 2: anatomical study. Neurosurgery 1979;5(4):447-451

28 Warner JP, Krushell RJ, Masquelet A, Gerber C. Anatomy and relationships of the suprascapular nerve: anatomical constraints to mobilization of the supraspinatus and infraspinatus muscles in the management of massive rotator-cuff tears. J Bone Joint Surg Am 1992;74(1):36-45

29 Tubbs RS, Jones VL, Loukas M, et al. Anatomy and landmarks for branches of the brachial plexus: a vade mecum. Surg Radiol Anat 2010;32(3):261-270

30 Bodily KD, Spinner RJ, Shin AY, Bishop AT. Clinical significance of suprascapular nerve mobilization. Clin Anat 2005;18(8): 573-579

31 Agrawal V. Arthroscopic decompression of a bony suprascapular foramen. Arthroscopy 2009;25(3):325-328
32 Moen TC, Babatunde OM, Hsu SH, Ahmad CS, Levine WN. Suprascapular neuropathy: what does the literature show? J Shoulder Elbow Surg 2012;21(6):835-846

33 Kim DH, Murovic JA, Tiel RL, Kline DG. Management and outcomes of 42 surgical suprascapular nerve injuries and entrapments. Neurosurgery 2005;57(1):120-127, discussion 120-127

34 Jerosch J, Saad M, Greig M, Filler T. Suprascapular nerve block as a method of preemptive pain control in shoulder surgery. Knee Surg Sports Traumatol Arthrosc 2008;16(6):602-607

35 Vorster W, Lange CP, Briët RJ, et al. The sensory branch distribution of the suprascapular nerve: an anatomic study. J Shoulder Elbow Surg 2008;17(3):500-502

36 Lafosse L, Tomasi A. Technique for endoscopic release of suprascapular nerve entrapment at the suprascapular notch. Tech Shoulder Elbow Surg 2006;7:1-6

37 Mestdagh H, Drizenko A, Ghestem P. Bases anatomiques du syndrome du nerf sus-scapulaire (n. suprascapularis) [French]. Anat Clin 1981;3:67-71

38 Rengachary SS, Neff JP, Singer PA, Brackett CE. Suprascapular entrapment neuropathy: a clinical, anatomical, and comparative study. Part 1: clinical study. Neurosurgery 1979;5(4):441-446

39 Bora FW Jr, Pleasure DE, Didizian NA. A study of nerve regeneration and neuroma formation after nerve suture by various techniques. J Hand Surg Am 1976;1(2):138-143

40 Safran MR. Nerve injury about the shoulder in athletes, part 1: suprascapular nerve and axillary nerve. Am J Sports Med 2004; 32(3):803-819

41 Arboleya L, García A. Suprascapular nerve entrapment of occupational etiology: clinical and electrophysiological characteristics. Clin Exp Rheumatol 1993;11(6):665-668

42 Fabre T, Piton C, Leclouerec G, Gervais-Delion F, Durandeau A. Entrapment of the suprascapular nerve. J Bone Joint Surg Br 1999; 81(3):414-419

43 Roh MS, Wang VM, April EW, Pollock RG, Bigliani LU, Flatow EL. Anterior and posterior musculotendinous anatomy of the supraspinatus. J Shoulder Elbow Surg 2000;9(5):436-440

44 Meyer DC, Lajtai G, von Rechenberg B, Pfirrmann CW, Gerber C. Tendon retracts more than muscle in experimental chronic tears of the rotator cuff. J Bone Joint Surg Br 2006;88(11):1533-1538

45 Hersche $\mathrm{O}$, Gerber C. Passive tension in the supraspinatus musculotendinous unit after long-standing rupture of its tendon: a preliminary report. J Shoulder Elbow Surg 1998;7(4):393-396

46 Józsa L, Kannus P, Thöring J, Reffy A, Järvinen M, Kvist M. The effect of tenotomy and immobilisation on intramuscular connective tissue. A morphometric and microscopic study in rat calf muscles. J Bone Joint Surg Br 1990;72(2):293-297

47 Osterman AL. The double crush syndrome. Orthop Clin North Am 1988;19(1):147-155

48 Zahir KS, Zahir FS, Thomas JG, Dudrick SJ. The double-crush phenomenon-an unusual presentation and literature review. Conn Med 1999;63(9):535-538

49 Pruksakorn D, Sananpanich K, Khunamornpong S, Phudhichareonrat S, Chalidapong P. Posterior approach technique for accessory-suprascapular nerve transfer: a cadaveric study of the anatomical landmarks and number of myelinated axons. Clin Anat 2007;20(2):140-143

50 Post M. Diagnosis and treatment of suprascapular nerve entrapment. Clin Orthop Relat Res 1999;(368):92-100

51 Burkhart SS, Barth JR, Richards DP, Zlatkin MB, Larsen M. Arthroscopic repair of massive rotator cuff tears with stage 3 and 4 fatty degeneration. Arthroscopy 2007;23(4):347-354

52 Chalian M, Behzadi AH, Williams EH, Shores JT, Chhabra A. Highresolution magnetic resonance neurography in upper extremity neuropathy. Neuroimaging Clin N Am 2014;24(1):109-125

53 Schulte-Mattler WJ, Grimm T. Common and not so common nerve entrapment syndromes: diagnostics, clinical aspects and therapy [in German]. Nervenarzt 2015;86(2):133-141 